\title{
ANALYSIS OF FACTORS INFLUENCING THE ANNUAL ENERGY PRODUCTION OF PHOTOVOLTAIC SYSTEMS
}

\author{
David L. King, William E. Boyson, and Jay A. Kratochvil \\ Sandia National Laboratories, Albuquerque, NM, 87185-0752
}

\begin{abstract}
The most relevant basis for designing photovoltaic systems is their annual energy production, which is also the best metric for monitoring their long-term performance. An accurate array performance model based on established testing procedures is required to confidently predict energy available from the array. This model, coupled with the performance characteristics of other balance-of-system components, provides the tool necessary to calculate expected system performance and to compare actual versus expected energy production. Using such a tool, this paper quantifies the affect of the primary factors influencing the dc-energy available from different photovoltaic module technologies, and contrasts these influences with other system-level factors that often result in significantly less acenergy delivered to the load than the array is capable of providing. Annual as well as seasonal energy production is discussed in the context of both grid-tied and stand-alone photovoltaic systems.
\end{abstract}

\section{INTRODUCTION}

The performance of photovoltaic modules or arrays can be reported and compared in different ways, including: efficiency or peak power $\left(W_{p}\right)$ at the ASTM Standard Reporting Condition [1], cost per peak watt $\left(\$ W_{p}\right)$ [2], dcenergy normalized by peak power $\left(k W h / k W_{p}\right)[3,4]$, or average dc-energy produced per day $(\mathrm{kWh} / \mathrm{d})$. At the system level, performance is often judged based on daily ac-energy delivered $(\mathrm{kWh} / \mathrm{d}, \mathrm{ac})$ [5], and perhaps the most definitive performance metric quantifies actual energy cost $(\$ / k W h$, ac) where instaliation cost, operation and maintenance costs, and long-term component degradation rates are considered. Significant progress has now been made in understanding both the module-level and the system-level- factors that influence the annual energy production of both grid-tied and stand-alone photovoltaic systems [6].

\section{dc-ENERGY AVALABLE FROM PV MODULES}

The first step in analyzing the expected energy production from a photovoltaic system is to obtain an accurate estimate for the dc-energy available from the array, for the intended site and design configuration. The comprehensive outdoor testing procedures and array performance model developed by Sandia have now demonstrated good accuracy over a wide range of operating conditions, as documented elsewhere $[7,8,9]$. This performance model accounts for module specific electrical parameters, temperature coefficients, operating temperature as a function of environmental conditions, optical losses at high angles of incidence, solar spectral variation over the day, and module mounting orientation or tracking options. Using this model coupled with solar resource and weather data from the National Solar Radiation Data Base (NSRDB) [10], a sensitivity analysis of the factors influencing the energy available from commercial modules has been performed.

One valuable outcome from this analysis was a relative comparison of the annual energy available from different commercial module technologies. Table 1 gives the results for fourteen commercial technologies oriented at a latitude tilt-angle for three different sites, in terms of their expected annual-average dc-energy production per day. Results were scaled to the equivalent of a $1-\mathrm{kW}_{\mathrm{p}}$ array for each technology. Normalized values, with respect to the "mc-Si" module, are aiso shown for more direct comparison. An important conclusion from this anaiysis was that, given an equivalent power rating at the Standard Reporting Condition (SRC), all technology types were nominally equivalent in terms of expected annual energy production, within the uncertainty of the calcutation $( \pm 5 \%)$. This conclusion has also been recently supported in results reported by BP Solar [4]. The two exceptions in the table have manufacturer specific electrical characteristics (performance at the Standard Reporting Condition strongly limited by series resistance) that are likely to evolve making their annual energy production consistent with other modules.

\section{FACTORS INFLUENCING dC-ENERGY PRODUCTION}

The annual dc-energy produced by a photovoltaic module is influenced by a number of interactive factors, some related to the module itself and others related to the site environmental characteristics. The factors of most significance are the following: cumulative solar irradiance, module power rating at the Standard Reporting Condition, operating temperature (temperature coefficient influence), maximum-power-voltage $\left(\mathrm{V}_{\mathrm{mp}}\right)$ dependence on solar irradiance level, soiling, variation in solar spectrum, and optical losses when sunlight is at a high angle-of-incidence (AOI). The relative impact of these seven factors on annual energy production was investigated using our performance model. This effort will improve and simplify system design methods, and assist industry in rating and marketing photovoltaic modules. 
Table 1: Calculated annual-average dc-energy per day $(\mathrm{kWh} / \mathrm{d})$ available from different commercial photovoltaic technology types, all with identical $1-\mathrm{kW}$, ratings at the ASTM Standard Reporting Condition.

\begin{tabular}{|c|c|c|c|c|c|c|c|c|c|c|c|c|c|c|}
\hline \multicolumn{15}{|c|}{ Latitude-Tift Orientation, Open-Rack Mount (Uncertainty $+/-5 \%$ ) } \\
\hline \multirow{3}{*}{$\begin{array}{l}\text { Albuquerque } \\
\text { Sacramento } \\
\text { Buffalo }\end{array}$} & 5.82 & 5.87 & 5.81 & 5.78 & 5.79 & 5.88 & 5.95 & 5.67 & 6.46 & 5.80 & 6.07 & 5.73 & 6.56 & 5.74 \\
\hline & 4.90 & 4.95 & 4.87 & 4.84 & 4.86 & 4.95 & 5.01 & 4.72 & 5.43 & 4.83 & 5.03 & 4.83 & 5.65 & 4.78 \\
\hline & 3.87 & 3.89 & 3.85 & 3.81 & 3.83 & 3.97 & 3.85 & 3.74 & 4.24 & 3.80 & 3.92 & 3.87 & 4.25 & 3.71 \\
\hline \multirow{4}{*}{$\begin{array}{l}\text { Normalized } \\
\text { Albuquerque } \\
\text { Sacramento } \\
\text { Buffalo }\end{array}$} & mc-Si & mc-Si\#2 & mc-Si\#3 & $\mathrm{mc}-\mathrm{SiH4}$ & $\mathrm{mc}-\mathrm{Si}+5$ & c-Si & HIP-Si & $\mathrm{p}-\mathrm{Si}$ & $\mathbf{a}-\mathbf{S i}$ & a-Si\#2 & CIS & CdTe & CdTe\#2 & CdTe\#3 \\
\hline & 1.00 & 1.01 & 1.00 & 0.99 & 0.99 & 1.01 & 1.02 & 0.97 & 1.11 & 1.00 & 1.04 & 0.99 & 1.13 & 0.99 \\
\hline & 1.00 & 1.01 & 0.99 & 0.99 & 0.99 & 1.01 & 1.02 & 0.96 & 1.11 & 0.99 & 1.03 & 0.99 & 1.15 & 0.98 \\
\hline & 1.00 & 1.00 & 0.99 & 0.98 & 0.99 & 1.02 & 0.99 & 0.96 & 1.09 & 0.98 & 1.01 & 1.00 & 1.10 & 0.96 \\
\hline
\end{tabular}

\section{Cumulative Solar Irradiance}

The energy produced by a photovoltaic module over a year's period of time is directly related to the availability of solar energy, and as a result is site dependent. In Buffalo, NY, there is about $60 \%$ and in Sacramento, CA, about $85 \%$ of the solar energy available in Albuquerque, NM. The cumulative solar energy incident on a photovoltaic module is in turn strongly dependent on the module's orientation relative to the sun. To maximize energy production, the module can be mounted on a 2-axis solar tracker so that it always points directly at the sun. In other applications, it may be desirable to mount a module in a horizontal or vertical orientation. Generally, it is common practice to mount flat-plate modules on a structure orienting them at a tilt-angle from horizontal that is equal to the site latitude angle. This 'latitude-tilt' orientation provides a good annual compromise in capturing sunlight without the added expense of a solar tracker.

Table 2 shows annual energy available from a typical multi-crystalline silicon (mc-Si) module relative to a latitudetilt reference case for different module orientations and tracking options. The benefit of solar tracking was found to be site dependent with the greatest benefit for sites with a high percentage of direct beam solar irradiance, like Albuquerque. Module orientation also strongly influences the daily and monthly distribution of energy produced, making it possible for designers to better match photovoltaic energy production with energy demands that may be seasonally distributed. The seasonal distribution of dcenergy available for different module orientations in Albuquerque is shown in Figure 1.

Table 2: Influence of module orientation and tracking on annual dc-energy available from a mc-Si module, relative to a latitude-tilt orientation.

\begin{tabular}{|l|c|c|c|}
\hline & \multicolumn{3}{c}{ Albuquerque Sacramento Buffalo } \\
\cline { 2 - 4 } Laitude-Tilt & 1.00 & 1.00 & 1.00 \\
\cline { 2 - 4 } Horizontal & 0.86 & 0.90 & 0.90 \\
\cline { 2 - 4 } Vertical & 0.73 & 0.71 & 0.83 \\
\cline { 2 - 4 } 1-Axis Tracking & 1.21 & 1.23 & 1.15 \\
\cline { 2 - 4 } 2-Axis Tracking & 1.32 & 1.31 & 1.23 \\
\hline
\end{tabular}

\section{Maximum-Power-Voltage $\left(V_{\text {mp }}\right)$ vs. Irradiance}

This module-specific factor, or characteristic, is not typically measured or specified by module manufacturers, but it can have a pronounced influence on annual energy production. Basically, the factor describes how well a module performs at low irradiance levels. Figure 2 illustrates the $V_{m p}$ dependence on irradiance measured for two different modules. In the case of the amorphous silicon (a-Si) module shown, the $V_{m p}$ increased as the irradiance level decreased, thus maintaining an operating voltage at low irradiance levels higher than at the reference one-sun condition. This behavior can be important, particularly for sites with a high percentage of overcast sky conditions, because it can result in about $10 \%$ more annual energy production. The a-Si and CdTe\#2 modules in Table 1 had a noticeably higher annual energy production, primarily because of this $V_{m p}$ vs. irradiance effect. Relatively smaller temperature coefficients also contributed about $2 \%$ to the apparent energy production advantage for the a-Si module.

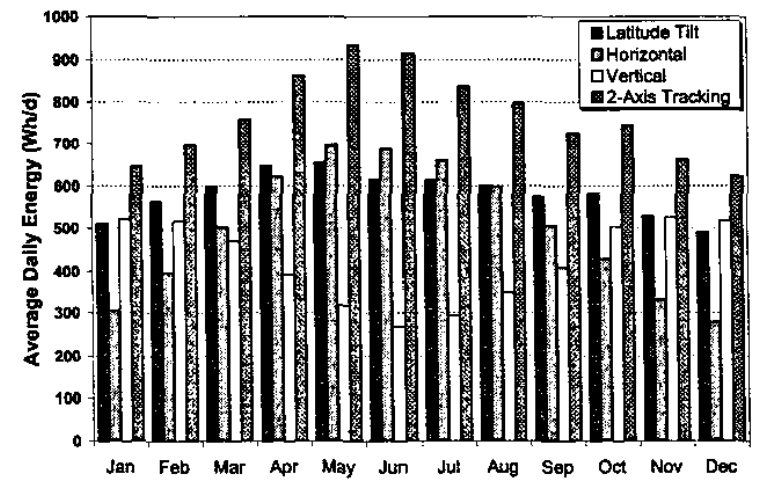

Fig.1: Calculated dc-energy available from a $100-W_{p} \mathrm{mc}-S i$ module by month in different orientations in Albuquerque.

\section{Operating Temperature and Temperature Coefficients}

Module performance changes with operating temperature, at a rate defined by the module's temperature coefficients. Both the electrical current generated by a module and its voltage are independently influenced by operating temperature. As temperature increases, voltage typically decreases and current typically increases, with the largest relative influence on voltage. As stated previously, the ASTM Standard Reporting Condition serves as the reference condition for module performance, with cell temperature specified to be $25^{\circ} \mathrm{C}$. Therefore, a module's relative performance and energy production will decrease during operating conditions where the cell temperature is 
above $25^{\circ} \mathrm{C}$. The operating temperature is influenced by module design (flat-plate, concentrator), mounting technique (open rack, roof mounted), irradiance level, ambient temperature, wind speed, and to a lesser degree wind direction. Sandia's empirically-based thermal model compensates for these influences and relates cell temperature to the environmental parameters given in the NSRDB database (irradiance, ambient temperature, wind speed). In the analysis presented here, the sensitivity of annual energy production to temperature coefficients was investigated by caiculating the ratio of annual energy, with temperature coefficients applied, divided by annual energy, assuming that module performance had no temperature dependence.

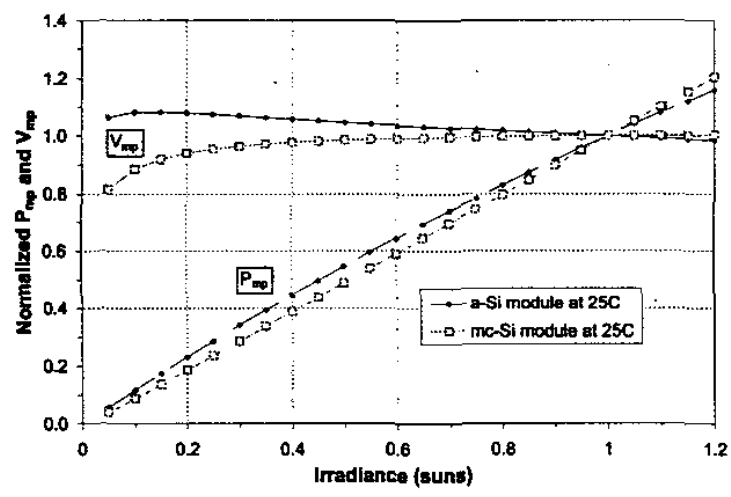

Fig. 2: $V_{m p}$ and $P_{m p}$ versus irradiance behavior measured for two different modules, a-Si and mc-Si.

Table 3 shows the results for the modules for three different sites. The temperature coefficients for $P_{\text {mp }}$ for the three modules shown were approximately $-0.5 \% / C$ for mc$\mathrm{Si},-0.25 \% / \mathrm{C}$ for $\mathrm{a}-\mathrm{Si}$, and $-0.4 \% / \mathrm{C}$ for the Si concentrator. The effect of operating temperature on annual energy production was found to be dependent on both module technology and site environmental conditions. However, the magnitude of the effect on annual energy production may be smaller than commonly assumed.

Table 3: Influence of module temperature coefficient on annual dc-energy available for different sites.

\begin{tabular}{|l|c|c|c|}
\hline & \multicolumn{1}{c}{$\mathrm{mC}-\mathrm{Si}$} & $\mathrm{a}-\mathrm{Si}$ & \multicolumn{1}{c|}{ Concentrator } \\
\cline { 2 - 4 } Albuquerque & 0.94 & 0.98 & 0.91 \\
\cline { 2 - 4 } Sacramento & 0.93 & 0.97 & 0.91 \\
\cline { 2 - 4 } Buffalo & 0.99 & 1.00 & 0.96 \\
\hline
\end{tabular}

\section{Variation in Solar Spectrum}

Quantifying the influence of the hourly variation in the solar spectrum on module energy production requires an academically complex procedure. Fortunately, as long as the $A M=1.5$ spectrum standardized by ASTM [11] is used as the reference for module power specification, the annual energy production from a module is relatively insensitive to solar spectral variation. The variations in module performance that occur during each day and over the seasons effectively average out on an annual basis. Table
4 illustrates the sensitivity of annual energy production to solar spectrum in terms of the ratio of calculated annual energy, with solar spectral influence included, divided by annual energy, assuming the module performance was not influenced by variations in the solar spectrum. The a-Si module considered had the strongest sensitivity, but the impact on annual energy production was still less than $3 \%$. The direct beam irradiance to which a concentrator module responds has relatively less variation in spectral distribution than does the global irradiance to which flat-plate modules respond. Therefore, the annual energy from the Si concentrator module showed little sensitivity to solar spectrum.

Table 4: Influence of variation in solar spectrum on annual dc-energy available for different sites.

\begin{tabular}{|l|c|c|c|}
\hline \multirow{3}{*}{$\begin{array}{l}\text { mc-Si } \\
\text { Albuquerque }\end{array}$} & \multicolumn{1}{c}{ a-Si } & Concentrator \\
\cline { 2 - 5 } Sacramento & 0.993 & 0.992 & 0.996 \\
\cline { 2 - 4 } Buffalo & 1.002 & 0.978 & 1.001 \\
\cline { 2 - 4 } & 1.004 & 0.973 & 1.001 \\
\hline
\end{tabular}

Even though the average annual impact on energy may be small, it is still important to understand the daily and seasonal influence that the varying solar spectrum has on module performance. Figure 3 illustrates the influence of variation in solar spectrum on the normalized short-circuitcurrent $\left(I_{s c}\right)$ over the day in Albuquerque, as the sun's elevation angle increases to noon and then decreases. For a sea-level site such as Sacramento, the curves shown would translate to the right by about $10 \mathrm{deg}$. The behavior illustrated in Figure 3 for a mc-Si and an a-Si moduie is dependent on the spectral response characteristics of the cells in the module. It is important for those conducting field measurements or monitoring array power data to understand this spectral influence. Measurements will be in error, relative to the ASTM standard reporting condition, by the factor shown, depending on the time-of-day that measurements are made.

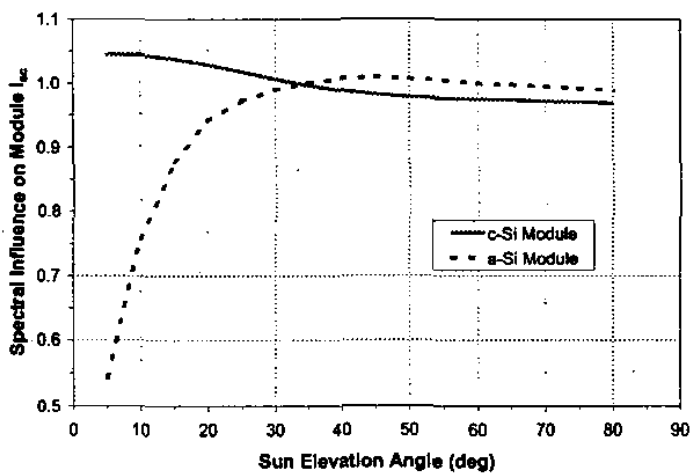

Fig. 3: Influence of a varying solar spectrum on module $I_{s c}$ as sun's elevation angle (air mass) varies over the day in Albuquerque, NM.

This spectral influence also has a seasonal effect on the energy produced by photovoltaic modules because in the summer the sun spends more time at high elevation angles (low air mass) than in the winter (high air mass). To illustrate this seasonal effect, daily average energy 
produced by month was calculated with the influence of solar spectrum considered, and these values were divided by energy produced, assuming no solar spectral dependence. Figure 4 shows the resulting ratios for a $\mathrm{mc}-\mathrm{Si}$ module and an a-Si module, both oriented at latitude-tilt in Albuquerque. Note that the spectral influence produces a seasonal variation in both technologies with the magnitude of the influence being noticeably larger for the a-Si module. This seasonal (summer versus winter) behavior for a-Si modules has been observed in long-term monitoring of a-Si systems, and is further augmented by a seasonal 'annealing' phenomenon that is still the subject of technical debate today [12].

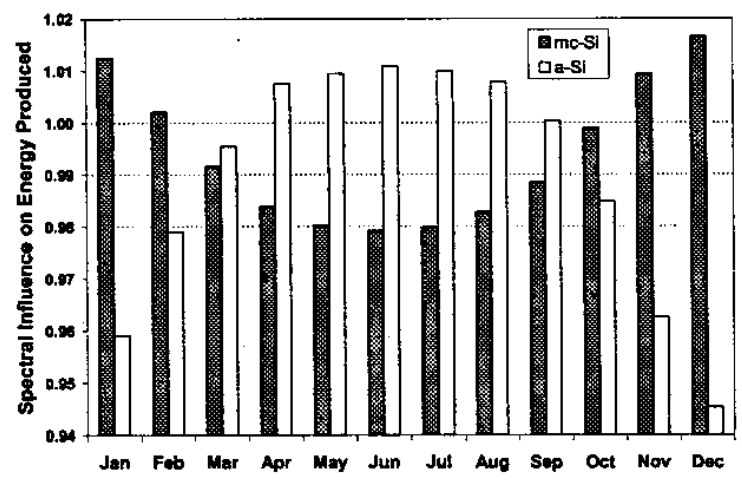

Fig. 4: Seasonal (monthly) influence of the varying solar spectrum on energy available from a mc-Si module and from an a-Si module in Albuquerque.

\section{Influence of Solar Angle-of-Incidence}

The final factor influencing the dc-energy available from modules is the effect of optical losses that vary with the angle-of-incidence (AOI) of sunlight striking the module. The effect relates primarily to the direct beam component of solar irradiance because the module's response to diffuse solar irradiance is largely independent of module orientation. For flat-plate modules, the optical loss is associated with the reflectance loss from the glass front surface. The reflectance of the glass surface increases significantly for $\mathrm{AOI}$ greater than about 60 degrees. The net result is less sunlight reaching the cells inside the module and reduced energy production for large angles-of-incidence. Like the influence of solar spectral variation, the influence of this optical loss on annual energy production is relatively small, but can have a significant seasonal (monthly) effect depending on the orientation of the module. Table 5 summarizes the $\mathrm{AOl}$ influence on annual energy production for a mc-Si module in four orientations at three different sites. There is no AOI related energy loss for a module mounted on a two-axis solar tracker ( $\mathrm{AOl}=0$ degrees). The largest effect on annual energy was small, about $4 \%$, for a vertically oriented module, and for the typical case of a module oriented at latitude-tilt the annual loss was only about $1 \%$. Figure 5 illustrates the measured influence of $\mathrm{AOI}$ on module performance for a variety of commercial modules. The seasonal (monthly) affect on energy production is illustrated in Figure 6 for a mc-Si module mounted horizontally or vertically in Albuquerque.
Particularly for building-integrated PV systems, the influence of $\mathrm{AOI}$ on the monthly energy production needs to be considered during system design.

Table 5: Influence of AOI optical losses on annual dc-energy available for different module orientations.

\begin{tabular}{|l|c|c|c|c|}
\hline \multicolumn{4}{c}{ 2-Axis } & \multicolumn{3}{c|}{ Lat.Tilt } & Horizontal & Vertical \\
\cline { 2 - 5 } Albuquerque & 1 & 0.989 & 0.976 & 0.960 \\
\cline { 2 - 5 } $\begin{array}{l}\text { Sacramento } \\
\text { Buffalo }\end{array}$ & 1 & 0.989 & 0.981 & 0.957 \\
\cline { 2 - 5 } & 1 & 0.993 & 0.985 & 0.975 \\
\hline
\end{tabular}

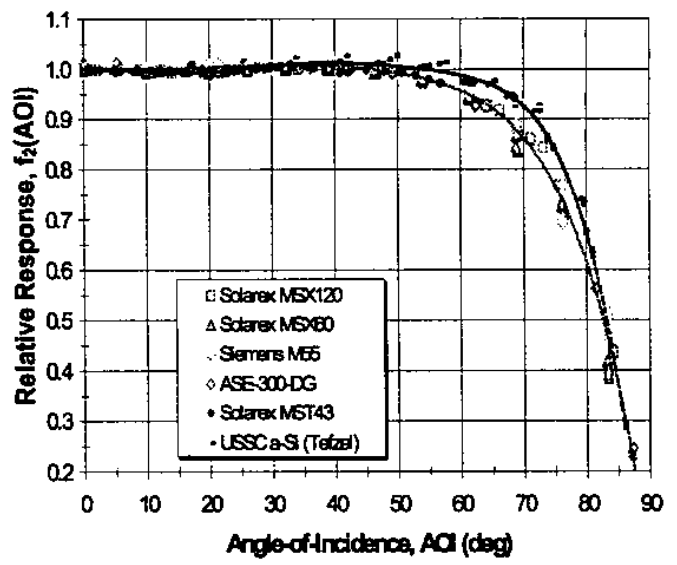

Fig. 5: Measured influence of optical loss on relative response of module Isc versus AOI for variety of modules.

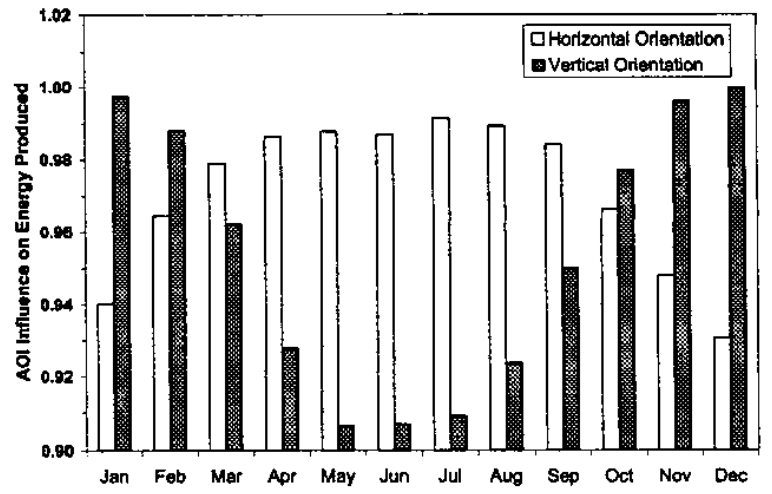

Fig. 6: Seasonal (monthly) influence of solar angle-ofincidence on energy produced by a mc-Si module with glass front surface.

\section{ac-ENERGY PROVIDED BY PV SYSTEMS}

Sandia's long-term goal is to understand all factors that influence photovoltaic system performance and reliability. Developing a fundamental understanding of the factors influencing the dc-energy available from individual photovoltaic modules is a significant step toward that goal. However, the module-level factors previously discussed in 
this report need to be put in perspective relative to systemlevel factors that can overwhelm them.

System-level factors may introduce energy losses due to module mismatch in the array, array soiling, wiring and terminal resistance, array performance degradation with age [13], and incompatibility of system components. In addition, grid-connected systems may have energy losses associated with inverter efficiency versus load and temperature, inverter tare loss, maximum-power-point-tracking (MPPT) efficiency, isolation transformer efficiency, etc. Stand-alone systems have additional dc-energy losses and system design constraints associated with charge-controller efficiency (utilization of dc-energy available from the array), battery capacity, battery charge and discharge efficiency, and design (sizing) tradeoffs in selecting a suitable ratio between dc-energy available from the array and the anticipated acenergy requirement. In poorly designed systems, combinations of these factors can quickly result in the inability of the system to power the intended load, constituting a 'system failure.'

Although the results are somewhat'site and module technology dependent, Table 6 is an attempt to categorize different factors that can influence system ac-energy production, along with the range of their potential impact. In Table 6, the influence of inverters and charge controllers are lumped into the factor called "power conversion, dc to ac." Several factors in the table have been previously discussed. Energy storage and array utilization associated with standalone photovoltaic systems are discussed in another paper at this conference [6]. In addition, module performance degradation mechanisms and rates are discussed elsewhere [13]. Field testing experience [7] has provided an estimate for the range of influence of module mismatch on array performance, for relatively new systems. However, this range is likely to be larger after several years of system operation as the module mismatch is likely to increase in magnitude. The issue of selecting power conditioning hardware (inverter) that is compatible with the photovoltaic array's operating characteristics has been a design issue for system integrators for many years [5]. Sandia's array performance modeling capabilities are now being used to assist system integrators in better matching array designs with inverter requirements.

Examples of the consequence of component selection on array utilization and resulting annual ac-energy production for two different grid-tied systems are illustrated in Figures 7, 8, and 9. Figure 7 illustrates a scatter plot of hourly values for the array maximum-power-voltage $\left(V_{m p}\right)$ versus the array maximum power level. Superimposed on the scatter plot is the 'input voltage window' for the inverter used in the system. For this situation, the inverter requirements did not match the $V_{m p}$ characteristics of the array, or vice versa, and the net result was significant energy loss due to reduced inverter efficiency.

Figures 8 and 9 illustrate a situation where the same grid-tied system design was being considered for two sites with distinctly different environmental conditions. In this case, the inverter selected had a wide MPPT voltage window $(250<\mathrm{V}<550 \mathrm{Vdc})$, a nominal input power rating of $2.5 \mathrm{~kW}$, and an upper limit of $2.7 \mathrm{~kW}$ above which power from the array was lost. Array performance modeling provided several results of critical importance to system design. For both sites, the range for array $V_{\text {mp }}$ was marginally above the lower limit $(250 \mathrm{Vdc})$ for inverter MPPT. The temperate climate in San Diego resulted in a narrow $V_{m p}$ scatter band compared to Madison where relatively large day to night and seasonal swings in ambient temperature occur. For the same array size, about $20 \%$ more annual dc-energy was available in San Diego than Madison. However, as shown by the cumulative power distribution curves, a higher percentage of the annual dcenergy available from the array in Madison exceeded the inverter input limit (2.7-kW) than in San Diego. In Madison, about $10 \%$ of the dc-energy available from the array was at a level exceeding the upper limit for the inverter, compared to about $3 \%$ in San Diego.

Table 6: Estimated ranges for the influence of module and system-level factors on the annual ac-energy available from photovoltaic systems.

\begin{tabular}{|l|c|}
\hline \multicolumn{1}{|c|}{ Factor } & Range (\%) \\
\hline Module orientation & -25 to +30 \\
\hline Energy storage (batteries) & -30 to -5 \\
\hline Array utilization losses (MPPT) & -30 to -5 \\
\hline Power conditioning hardware & -20 to -5 \\
\hline Module power specification & -15 to 0 \\
\hline Module temperature coefficients & -10 to -2 \\
\hline Module (array) degradation $(\% / y r)$ & -7 to -0.5 \\
\hline Module $V_{\text {mp }}$ vs. Irradiance & -5 to +5 \\
\hline Module soiling (annual average) & -10 to 0 \\
\hline Angle-of-incidence optical losses & -5 to 0 \\
\hline Module mismatch in array & -5 to 0 \\
\hline Solar spectral variation & -3 to +1 \\
\hline
\end{tabular}

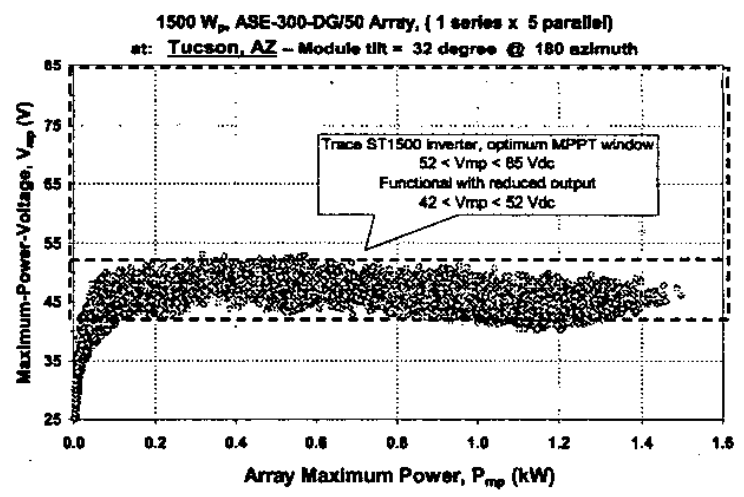

Fig. 7: Scatter plot of hourfy-average $V_{m p}$ values for a 1.5$\mathrm{kW}_{\mathrm{p}}$ array versus array maximum power level for system located in Tucson, $A Z$. The maximum-power-point-tracking windows for the grid-tied inverter are shown. The inverter functions in the lower window, but at a reduced efficiency. 


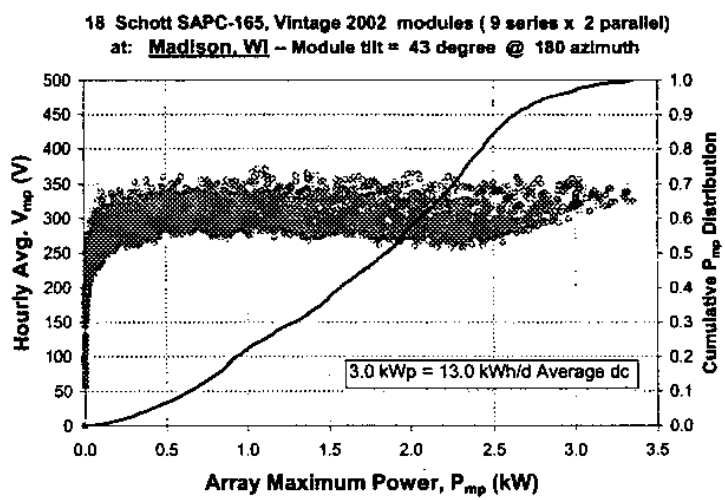

Fig. 8: Scatter plot of hourly-average $V_{m p}$ values for a 3.0$\mathrm{kW}_{\mathrm{p}}$ array versus array maximum power level for system located in Madison, WI. The cumulative distribution curve for power is also shown.

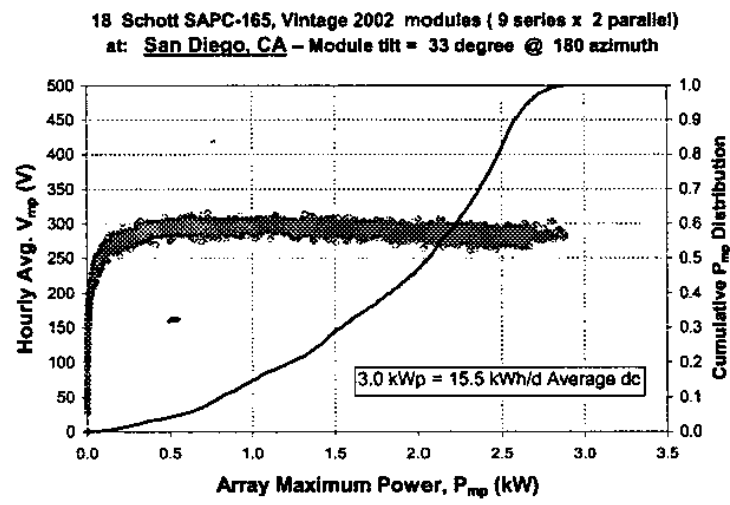

Fig. 9: Scatter plot of hourly-average $V_{\text {mp }}$ values for a 3.0$\mathrm{kW}_{\mathrm{p}}$ array versus array maximum power level for system located. in San Diego, CA.

\section{CONCLUSIONS}

It is clear from this work there are many factors that can have a significant influence on the ac-energy production and reliability of photovoltaic systems. The continued evolution of system testing and performance modeling procedures will improve the ability of system integrators to design, install, and monitor the performance of systems. These improvements will lead to photovoltaic systems with high performance and high reliability at a minimum cost.

\section{ACKNOWLEDGEMENTS}

The authors would like to acknowledge valuable discussions with the following: Bob Hammond (APS), Jim Rand (AstroPower), John Wohlgemuth (BP Solar), Chuck Whitaker (Endecon), Ron Orozco (Energia Total), Dan Shugar (PowerLight), Georg Schultz (RUS), Miles Russell (SAPC), Tom Hansen (TEP), and Moneer Azzam (Solar Dynamics). [Sandia is a multi-program laboratory operated by Sandia Corporation, a Lockheed Martin Company, for the
United States Department of Energy under Contract DEACO4-94AL85000.]

\section{REFERENCES}

[1] ASTM E 1036, "Testing Electrical Performance of Nonconcentrator Photovoltaic Modules and Arrays Using Reference Cells."

[2] Anon., "Solar-Electric Power: The U.S. Photovoltaic Industry Roadmap," April 2001.

[3] T. Townsend, et al., "A New Performance Index for PV System Analysis," $1^{\text {st }}$ WCPEC, 1994, pp. 1036-1039.

[4] S. Ransome and J. Wohlgemuth, "kWh/kWp Dependency on PV Technology, Balance of Systems Performance, and Marketing Watts," $29^{\text {th }}$ IEEE PVSC, 2002, New Orleans.

[5] M. C. Russell, "Grid-Tied PV System Modeling: How and Why," $1^{\text {st }}$ WCPEC, 1994, pp. 1040-1043.

[6] D. King, et al., "Experimental Optimization of the Performance and Reliability of Stand-Alone Photovoltaic Systems," $29^{\text {th }}$ IEEE PVSC, 2002, New Orleans.

[7] D. King, et al., "Field Experience with a New Performance Characterization Procedure for Photovoltaic Arrays," $2^{\text {nd }}$ World PVSEC, 1998, pp. 1947-1952.

[8] C. Whitaker, et al., "Application and Validation of a New PV Performance Characterization Method," $26^{\text {th }}$ IEEE PVSC, 1997, pp. 1253-1256.

[9] B. Kroposki, et al., "Comparison of Module Performance Characterization Methods," $28^{\text {th }}$ IEEE PVSC, 2000, pp. 1407-1411.

[10] Anon., "NSRDB Vol.2, National Solar Radiation Data Base, 1961-1990," NRELTP-463-5784, 1995.

[11] ASTM E 892, "Terrestrial Solar Spectral Irradiance at Air Mass 1.5 for a $37^{\circ}$ Tilted Surface."

[12] J. Wohlgemuth and S. Ransome, "Performance of BP Solar Tandem Junction Amorphous Silicon Modules," $29^{\text {th }}$ IEEE PVSC, 2002, New Orleans.

[13] M. Quintana, et al., "Commonly Observed Degradation in Field-Aged Photovoltaic Modules," $29^{\text {th }}$ IEEE PVSC, 2002, New Orleans. 